\title{
Sintomas músculo-esqueléticos em graduandos de enfermagem
}

Recebido em: 12/07/2012

Aceito em: 30/01/2013
Aline Caldas Martins ${ }^{1}$ Vanda Elisa Andres Felli²

As afecções músculo-esqueléticas relacionadas ao trabalho representam o principal grupo de agravos à saúde entre as doenças ocupacionais. Esta é uma pesquisa exploratório-descritiva, realizada em uma universidade pública do estado de São Paulo, com o objetivo de investigar a ocorrência de sintomas músculo-esqueléticos entre os graduandos de Enfermagem. Os dados foram coletados através de questionário composto por dados sociodemográficos e pelo Questionário Nórdico de Sintomas Músculo-esqueléticos. Os resultados evidenciaram a participação de 51 alunos, e todos apresentaram algum sintoma músculo-esquelético nos últimos 12 meses. O estudo aponta a necessidade de abordar temas relacionados à saúde do trabalhador durante a graduação.

Descritores: Saúde do Trabalhador, Ensino Superior, Transtornos Traumáticos Cumulativos.

\section{Musculoskeletal symptoms in undergraduate students of nursing}

The work-related musculoskeletal symptoms represent the main group of risks among the occupational diseases. This is an exploratory, descriptive research, carried out in a public university in the State of São Paulo, aiming to investigate the occurrence of musculoskeletal symptoms among the undergraduate students of Nursing. The data were collected through a questionnaire comprised by socio-demographic data and the Nordic Musculoskeletal Questionnaire Symptoms. 51 students participated in the study and the results showed that all of them experienced some musculoskeletal symptom in the last 12 months. The study points out the need for approaching themes related to occupational health in the curriculum framework of undergraduate studies.

Descriptors: Occupational Health, Higher Education, Cumulative Traumatic Disorders.

\section{Síntomas musculares y esqueléticos en graduados en enfermería}

Las afecciones musculares y esqueléticas relacionadas al trabajo representan el principal grupo de agravios a la salud entre las enfermedades ocupacionales. Esta es una investigación exploratoria y descriptiva, llevada a cabo en una universidad pública del Estado de San Pablo, con el objetivo de investigar la ocurrencia de síntomas musculares y esqueléticos entre los graduandos en Enfermería. Los datos fueron colectados a través de un cuestionario compuesto por datos sociodemográficos y por el Cuestionario Nórdico de Síntomas Musculares y Esqueléticos. Los resultados pusieron en evidencia la participación de 51 alumnos, y todos presentaron algún síntoma muscular o esquelético en los últimos 12 meses. El estudio apunta a la necesidad de abordar temas relacionados a la salud del trabajador durante la graduación.

Descriptores: Salud del Trabajador, Enseñanza Superior, Trastornos Traumáticos Cumulativos.

\section{INTRODUÇÃO}

A $\mathrm{s}$ afecções músculo-esqueléticas relacionadas ao trabalho, que no Brasil são denominadas Lesões por Esforços Repetitivos (LER), e atualmente de Distúrbios Osteomusculares Relacionados ao Trabalho (DORT), representam o principal grupo de agravos à saúde, entre as doenças ocupacionais do país(1).

É um grupo heterogêneo de distúrbios funcionais e/ou orgânicos que apresentam, entre outras, as seguintes características: indução por fadiga neuromuscular causada por trabalho realizado em posição fixa (estática) ou com movimentos repetitivos, principalmente de membros superiores; falta de tempo de recuperação pós-contração e fadiga (inflexibilidade de tempo, ritmo acelerado de trabalho); quadro clínico variado, incluindo dor, formigamento, dormência, choque, peso e fadiga precoce; presença de entidades ortopédicas definidas, como tendinite, tenossinovite, sinovite, dedo em gatilho, síndrome do túnel do carpo, síndrome cervical, entre outras; presença de quadros onde as repercussões são mais extensas ou generalizadas, como síndrome miofascial, mialgia, síndrome da tensão do pescoço, distrofia simpático-reflexa e síndrome complexa de dor regional(1).

LER/DORT são definidas como afecções músculo-esqueléticas onde o ambiente e condições de trabalho contribuem para seu aparecimento, e podem piorar por causa dessas mesmas condições, que incluem: movimentos repetitivos, aplicação de forças, principalmente com as mãos, levantamento e transporte de pesos, posturas inadequadas e estresse relacionado às condições psicossociais onde o trabalho acontece. O aparecimento das afecções está ligado à exposição dos trabalhadores a esses riscos e sua magnitude depende da intensidade, frequência e duração da

1 Enfermeira. Doutoranda do Programa de Pós-graduação de Gerenciamento de Enfermagem, da Escola de Enfermagem da Universidade de São Paulo. E-mail: aline.caldas. martins@usp.br.

2 Enfermeira. Professora Associada do Departamento de Orientação Profissional da Escola de Enfermagem da Universidade de São Paulo. 
exposição, e da capacidade individual de lidar com as exigências do trabalho ${ }^{(3,4)}$.

Para identificar o trabalho como causa das LER/DORT, são realizadas avaliações ocupacionais que abrangem uma análise das atividades de trabalho, e avaliações clínicas com exames físicos detalhados, relacionando-se posteriormente os sinais e sintomas encontrados às situações de trabalho observadas ${ }^{(2)}$.

Os trabalhadores acometidos por LER/DORT vivenciam uma rotina que envolve a busca constante de tratamento, dificuldade de confirmar a existência da doença, descrédito por parte dos familiares e amigos, falta de perspectivas futuras associada à incapacidade para o trabalho e perda da sua identidade como trabalhador, gerando sofrimento mental. Além disso, a doença incide negativamente ao limitá-los na execução de tarefas simples, domésticas ou profissionais ${ }^{(5)}$.

Outra informação relevante é que a incidência de LER/DORT é maior no sexo feminino, justificada por questões hormonais, pela dupla jornada de trabalho, pela falta de preparo muscular para determinadas tarefas e também pelo aumento do número de mulheres no mercado de trabalho ${ }^{(3,6,-8)}$.

O perfil de morbidade dos trabalhadores de enfermagem revela que as doenças, em especial as relacionadas ao aparelho músculo-esquelético, estão acometendo muito mais profissionais do que se imagina, repercutindo diretamente na prestação dos serviços de saúde ${ }^{(9)}$.

O ramo de atividade de serviços de saúde merece destaque quanto ao acometimento por LER/DORT, pois, além de ter sofrido impactos na sua reestruturação produtiva - como terceirização e uso intensivo de novas tecnologias - elevou sua participação na incidência das LER/DORT de 4,7\% em 1993 para 11,5\% em 1998, passando do oitavo para o quarto lugar no período ${ }^{(8)}$.

Os trabalhadores de enfermagem submetem-se constantemente a condições de trabalho inadequadas, extrapolando as inúmeras habilidades exigidas no desempenho das suas funções. Portanto, estão sujeitos às doenças relacionadas ao trabalho, incluindo as lesões músculo-esqueléticas, atribuídas principalmente a fatores ergonômicos e posturais inadequados ${ }^{(9)}$.

Ascargasfisiológicas relacionadas ao trabalho de enfermagem incluem o esforço físico pesado, decorrente do levantamento e manipulação de pesos, a posição de trabalho incômoda, pelo trabalho em pé por longos períodos e alternância dos turnos. Essas cargas são geradas pelas formas de organização e divisão do trabalho de enfermagem, quando da distribuição dessas atividades entre as diferentes categorias de trabalhadores. Contando com um número reduzido de trabalhadores para a realização das atividades, favorece-se a sobrecarga individual do trabalhador e para aqueles que, no seu conjunto, assumem os cuidados que envolvem a manipulação de peso excessivo ${ }^{(10)}$.

Outro fato que chama a atenção é em relação ao grau de desconhecimento dos trabalhadores sobre o processo patológico vivenciado, devido às informações incompletas e contraditórias fornecidas pelos profissionais que lidam com o trabalhador doente, a pouca veiculação pela mídia de assuntos relacionados aos agravos à saúde do trabalhador, e à falta de grupos educativos que trabalhem informações como sintomas, causas e opções terapêuticas com as classes trabalhadoras em risco ao desenvolvimento de LER/DORT ${ }^{(5)}$.

Os estudantes de enfermagem realizam estágios curriculares onde aprendem e treinam procedimentos relativos à assistência de enfermagem como higiene dos pacientes, arrumação de leitos, realização de curativos, transporte e manipulação de pacientes, preenchimento de impressos hospitalares e anotações em prontuário, entre outros. Com isso, realizam procedimentos adotando posturas inadequadas, com manipulação excessiva de pesos, deslocando-se várias vezes na busca de materiais, à semelhança dos enfermeiros. Desta forma, também estão expostos aos distúrbios osteomusculares. No entanto, foram encontrados na literatura pesquisada estudos sobre a exposição de estudantes de enfermagem.

Esta situação é preocupante porque permite antever a piora dos sintomas na vida profissional, prejudicando a qualidade de vida atual e futura. Também permite considerar a necessidade de identificar essa problemática e propor medidas que minimizem a exposição desses estudantes em atividades curriculares.

Diante do exposto, motivamo-nos a investigar o conhecimento dos alunos de enfermagem sobre LER/ DORT, bem como a ocorrência de sintomas músculo-esqueléticos nessa população. Os objetivos deste trabalho são: avaliar o acometimento de alunos de graduação em enfermagem por sintomas músculo-esqueléticos e relacionar os dados obtidos com as atividades de vida diária e curriculares do grupo estudado.

\section{METODOLOGIA}

Esta é uma pesquisa exploratório-descritiva, quantitativa, realizada em uma universidade pública do estado de São Paulo. A população foi constituída pelos estudantes de enfermagem, que totalizaram 320 pessoas e a amostra intencional por conveniência reuniu os alunos matriculados no $3^{\circ}$ e $4^{\circ}$ anos do curso de graduação em enfermagem $(n=152)$, por constituírem o grupo que vivencia atividades profissionais em estágios nas instituições de saúde. Após aprovação do Comitê de Ética da instituição, sob protocolo $n^{\circ} 71 / 2008$, coletaram-se as informações através de um questionário composto por dados sociodemográficos dos participantes e pelo Questionário Nórdico de Sintomas Músculo-esqueléticos. Os dados quantitativos foram armazenados em planilha eletrônica Microsoft Office Excel ${ }^{\circledR}$, e posteriormente analisados. 


\section{RESULTADOS}

\section{Dados sociodemográficos}

A população estudada foi composta por 51 pessoas, que representam $33,55 \%$ do total de alunos matriculados no $3^{\circ} \mathrm{e}$ $4^{\circ}$ anos de graduação. Dos participantes, 46 pertencem ao sexo feminino (90,2 \%) e cinco pertencem ao sexo masculino (9,8\%). A idade média é de 23 anos, variando de 19 a 42 anos. O peso médio é de 60,84 kg, com máximo de 129 e mínimo de $48 \mathrm{~kg}$. A altura média obtida foi de 1,65 m, com variação de 1,48 a 1,90m. O Índice de Massa Corpórea (IMC) médio obtido foi de $22,3 \mathrm{~kg} / \mathrm{m}^{2}$, demonstrando que, de maneira geral, a população estudada apresenta-se na faixa de normalidade preconizada para esse índice. Quanto ao estado civil, 90,3\% dos participantes declaram-se solteiros, $8 \%$ são casados e 1,6\% dizem ser "amasiados", sendo que apenas 3,22\% têm filhos. A maioria das pessoas (70\%) mora com os pais, $72 \%$ dizem realizar atividades domésticas e $10 \%$ dos alunos trabalham, sendo todos do $4^{\circ}$ ano de graduação, principalmente como estagiários de enfermagem, em média 22,8 horas semanais. $58,85 \%$ dos participantes realizam iniciação científica.

Os meios de transporte mais usados para chegar à faculdade são ônibus (69\%), metrô (40\%) e carro (19,5\%). Apenas 9\% das pessoas realizam esse percurso caminhando. Já $65 \%$ dos participantes utilizam apenas um meio de transporte para chegar à faculdade, 30,4\% utilizam dois meios de transporte e $4,1 \%$ utilizam três meios de transporte. O tempo médio gasto nesse percurso é de 63 minutos, variando de 5 a 210 minutos.

Apenas $37,74 \%$ dos participantes dizem realizar atividade física regularmente, por aproximadamente três dias na semana, e em média 2 horas por dia. Os tipos de atividade física mais realizados são: musculação, natação, vôlei, fitness, corrida e caminhada.

Das atividades de lazer realizadas, as mais frequentes são: ir ao cinema/teatro (78,7\%), ver TV $(77,25 \%)$ e utilizar o computador $(75,48 \%)$. Apenas $25 \%$ dos participantes dizem praticar esporte como atividade de lazer. O computador é utilizado, em média, por 114 minutos ao dia, variando de 15 a 240 minutos. Os participantes relatam dormir, em média, 6 h por dia.

\section{Questionário Nórdico de Sintomas Músculo-esqueléticos}

O Questionário Nórdico de Sintomas Músculo-esqueléticos contém uma figura humana vista pela região posterior, dividida em nove regiões: região cervical, ombros, região torácica, cotovelos, punhos/mãos, região lombar, quadril/coxas, joelhos, tornozelos/pés. São feitas questões relacionadas com cada área anatômica, verificando se os respondentes tiveram dores nos últimos 12 meses e sete dias; procuram também investigar se essas pessoas foram impedidas de realizar suas atividades diárias e se procuraram auxílio médico nos últimos 12 meses devido aos mesmos sintomas.

Todos os estudantes de enfermagem que participaram da entrevista relataram ter pelo menos um sintoma músculo-esquelético nos últimos 12 meses. O segmento corpóreo mais afetado foi o pescoço $(74,5 \%)$, seguido pela região inferior das costas $(68,62 \%)$ e ombros $(64,7 \%)$. O gráfico abaixo mostra a ocorrência de sintomas músculo-esqueléticos nos últimos 12 meses.

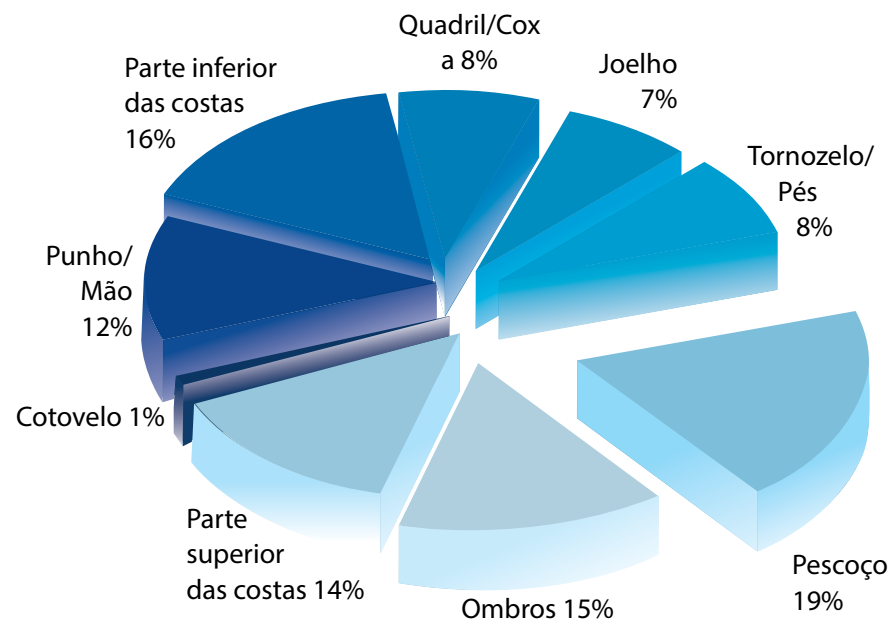

Gráfico 1 - Porcentagem de ocorrência de sintomas músculo-esqueléticos relatados pelos estudantes de graduação em Enfermagem nos últimos 12 meses, nas diferentes regiões corpóreas. São Paulo, 2008.

Os participantes também relataram a ocorrência de sintomas músculo-esqueléticos nos últimos sete dias com grande frequência, sendo a região inferior das costas $(35,29 \%)$, o pescoço $(33,33 \%)$ e os ombros $(29,41 \%)$, os segmentos corpóreos mais afetados.

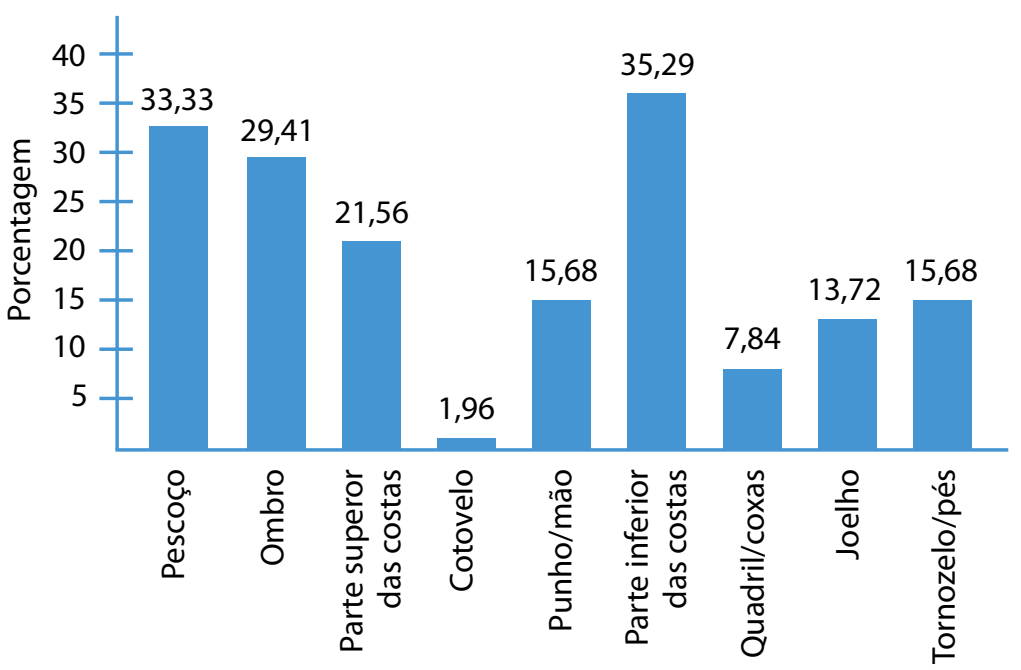

Gráfico 2 - Porcentagem de ocorrência de sintomas músculo-esqueléticos relatados pelos estudantes de graduação em Enfermagem, nos últimos sete dias, nas diferentes regiões corpóreas. São Paulo, 2008.

Apesar da alta ocorrência de sintomas músculoesqueléticos entre a população estudada, poucas pessoas foram impedidas de realizar suas atividades diárias devido a esse problema, e uma pequena parcela dos participantes procurou algum profissional de saúde por causa desses sintomas, como mostra a tabela 1. 
Tabela 1 - Porcentagem de relatos de impedimento das atividades diárias e de procura de profissional da saúde devido a sintomas músculo-esqueléticos pelos graduandos de Enfermagem. São Paulo, 2008.

\begin{tabular}{|l|l|l|}
\hline Regiäo do corpo & Impedimento & $\begin{array}{l}\text { Procura por } \\
\text { Profissional } \\
\text { de saúde }\end{array}$ \\
\hline Pescoço & $\%$ & $\%$ \\
\hline Ombros & 17,64 & 5,88 \\
\hline $\begin{array}{l}\text { Parte superior } \\
\text { das costas }\end{array}$ & 15,68 & 5,88 \\
Cotovelo & 7,84 & 3,92 \\
\hline Punho/mão & 1,96 & 1,96 \\
\hline $\begin{array}{l}\text { Parte inferior } \\
\text { das costas }\end{array}$ & 19,6 & 5,88 \\
\hline Quadril/coxa & 23,52 & 7,84 \\
\hline Joelho & 5,88 & 0 \\
\hline Tornozelo/pés & 15,68 & 5,88 \\
\hline
\end{tabular}

\section{DISCUSSÃO}

\section{Dados sociodemográficos}

Os dados coincidem com estudo realizado, onde constatouse que $90 \%$ dos estudantes que ingressaram na Escola de Enfermagem da Universidade de São Paulo (EEUSP) em 2003 eram do sexo feminino, que $95 \%$ encontrava-se na faixa etária de 20 a 25 anos, 66,7\% residiam com os pais, a maioria deles gastava 1 hora ou mais do local da residência à escola. Nenhum relatou praticar atividade física nas horas de lazer ${ }^{(11)}$.

Confirmando a tendência observada nos cursos de Enfermagem em todo o país, a grande maioria dos estudantes pertence ao sexo feminino, que sempre esteve associado às práticas de cuidado ${ }^{(12)}$.

Os participantes foram questionados sobre a realização de atividades domésticas, pois algumas dessas atividades, juntamente com outros hábitos diários, podem contribuir para o surgimento de sintomas músculo-esqueléticos. O uso excessivo do computador e as atividades domésticas com movimentos repetitivos, como lavar e passar roupa, lavar louça e limpar vidros, entre outros, podem agravar os quadros de dor osteomuscular, mas não podem ser consideradas causas isoladas desse sintoma, por apresentarem flexibilidade de ritmo e tempo ${ }^{(13)}$.

Percebemos também que, de maneira geral, os estudantes de enfermagem não praticam atividade física regularmente, e utilizam o computador por um longo período. O sedentarismo, associado ao pouco tempo de descanso e à carga de atividades curriculares, contribui para o surgimento de agravos à saúde.

Estudos mostram que pessoas que praticam exercícios físicos regularmente apresentam níveis de severidade de sintomas músculo-esqueléticos menores que aquelas pessoas que não praticam atividade física ${ }^{(14)}$.

\section{Questionário Nórdico de Sintomas Músculo-esqueléticos}

Os dados obtidos através do Questionário Nórdico mostram que os estudantes de graduação em enfermagem são um grupo acometido por sintomas músculo-esqueléticos.

Diversos estudos apontam que os profissionais de enfermagem são um grupo de risco para o desenvolvimento desses sintomas. As quatro regiões mais afetadas nesses trabalhadores são a região lombar, os ombros, joelhos e a região cervical ${ }^{(15-18)}$.

A dor lombar tem sido particularmente bem estudada entre os trabalhadores de saúde, sendo resultado de traumas cumulativos. As lesões dorsais ocupacionais ocorrem mais frequentemente quando é realizado o cuidado direto ao paciente, durante a mobilização e transporte dos mesmo ${ }^{(15-17)}$.

Comenta-se que as estruturas do corpo constituem uma unidade; portanto, a lesão em uma de suas estruturas pode provocar lesões em outras, uma vez que, na presença de inflamação ou degeneração das estruturas músculo-esqueléticas, o trabalhador mobiliza outros para poupá-las e, assim, as regiões hipersolicitadas ou sobrecarregadas acabam por sofrer, também, processo inflamatório e/ou degenerativo ${ }^{(17)}$.

Como percebemos através da tabela 1, mesmo apresentando sintomas músculo-esqueléticos, poucas pessoas foram impedidas de realizar suas atividades diárias devido a esses sintomas, e uma pequena parcela dos participantes procurou algum profissional de saúde.

Estudos apontam que os trabalhadores de um modo geral tendem a banalizar a própria saúde, pois o adoecer na sociedade capitalista é vergonhoso por constituir um empecilho à produção, e deve ser ocultado, quando não, negado ${ }^{(19)}$.

Além desse fator, existe a dificuldade para conseguir consultas e tratamentos médicos, aliada à falta de tempo que as pessoas alegam para buscar o cuidado à própria saúde. Desta forma, muitas vezes os profissionais de enfermagem (incluindo aqui os estudantes), passam a conviver com os sintomas músculo-esqueléticos e não buscam diagnóstico nem tratamento para suas dores.

\section{CONCLUSÃO}

O perfil dos estudantes de graduação em enfermagem mantémse semelhante ao dos profissionais, segundo estudos realizados anteriormente. São em sua maioria mulheres, jovens, solteiras e sem filhos, que moram com os pais e não trabalham. Observamos que mais da metade dos alunos participa de iniciação científica e não pratica atividade física regularmente, além de utilizar o computador por aproximadamente duas horas por dia.

De maneira geral, os alunos demonstraram um desconhecimento importante sobre doenças relacionadas ao trabalho, mas os estudantes do $3^{\circ}$ ano reportaram menos conhecimento do que os do $4^{\circ}$ ano. Tal fato pode estar relacionado com a disciplina de Administração de Enfermagem, que é ministrada no 70 semestre da graduação, onde são abordados assuntos sobre a saúde do trabalhador e os alunos presenciam a ocorrência de LER/DORT dentre os trabalhadores dos campos de estágio, além de outras doenças ocupacionais. 
Mesmo assim, alguns participantes conseguem citar sintomas e fatores de risco para a ocorrência de LER/DORT, e identificam os trabalhadores e estudantes de enfermagem como grupos de risco para o desenvolvimento desse distúrbio.

As respostas ao Questionário Nórdico permitiram identificar que todos os alunos apresentaram algum sintoma músculo-esquelético nos últimos 12 meses e quase $50 \%$ deles foram impedidos de realizar suas atividades rotineiras por esse problema, mas apenas $25 \%$ dos participantes procuraram algum profissional da área de saúde por esta condição.

Concluímos que os estudantes de graduação em enfermagem são um grupo acometido por sintomas músculo-esqueléticos, e realizam atividades diárias que podem contribuir para o surgimento de LER/DORT.

Oestudo aponta para a necessidade deabordar precocemente temas relacionados à saúde do trabalhador de enfermagem durante a graduação, capacitando o aluno a detectar condutas de risco e prevenindo o surgimento de doenças ocupacionais, principalmente LER/DORT consigo, com seus colegas e com trabalhadores da equipe de saúde. Também é importante que essa discussão permeie as mudanças curriculares dos cursos de graduação de enfermagem.

\section{Referências}

1. Settimi MM, Ministério da Saúde (BR). Secretaria de Políticas de Saúde. Centro de Estudos em Saúde do Trabalhador. Lesões por Esforços Repetitivos (LER)/ Distúrbios Osteomusculares Relacionados ao Trabalho (DORT). Brasilia (DF): Ministério da Saúde; 2000

2. Rosa AFG, Garcia PA, Vedoato T, Campos RG, Lopes MLS. Incidência de LER/ DORT em trabalhadores de enfermagem. Acta Scientiarum Health Sciences. 2008; 30(1): 19-25.

3. Przysiezny WL. Distúrbios osteomusculares relacionados ao trabalho: um enfoque ergonômico [dissertação]. Santa Catarina: Universidade Federal de Santa Catarina; 2003.

4. Carugno M, Pesatori AC, Ferrario MM, Ferrari AL, Silva FJ, Martins AC et al. Physical and psychosocial risk factors for musculoskeletal disorders in Brazilian and Italian nurses. Cad. Saúde Pública, Rio de Janeiro, 28(9):1632-1642, set, 2012. 5. Souza AC, Coluci MZO, Alexandre NMC. Sintomas osteomusculares em trabalhadores da enfermagem: uma revisão integrativa. Ciência, Cuidado e Saúde. 2009; 8(4):683-690.

6. Ghislent AP, Merlo ARC. Trabalhador contemporâneo e patologias por

hipersolicitação. PsicolReflexCrit. 2005;18(2):171-76.

7. Freitas JRS, Lunardi Filho WD, Lunardi VL, Freitas KSS. Distúrbios

osteomusculares relacionados ao trabalho em profissionais de enfermagem de um hospital universitário. Revista Eletrônica de Enfermagem. 2009; 11(4):904-11. 8. Salim CA. Doenças do trabalho: exclusão, segregação e relações de gênero. São Paulo Perspec. 2003;17(1):11-24.

9. Leite PC. A vivência de mulheres trabalhadoras de enfermagem que

apresentam DORT [tese]. São Paulo: Escola de Enfermagem, Universidade de São Paulo; 2006.

10. Felli VEA, Tronchin DMR. A qualidade de vida e a saúde do trabalhador de enfermagem. In: Kurcgant P, organizador. Gerenciamento em enfermagem. Rio de Janeiro: Guanabara Koogan; 2010. p.85-103

11. Oguisso T, Lira PS, Vieira APM, Pereira KCM, Mesquita MMC, Silva PJP. Perfil do estudante ingressante no Curso de Graduação da Escola de Enfermagem da Universidade de São Paulo. Rev Paul Enferm. 2006;25(2):109-16.

12. Coelho EAC. Gênero, saúde e enfermagem. RevBrasEnferm. 2005;58(3):345-8. 13. Helfestein Júnior M. Lesōes por Esforços Repetitivos ou Distúrbios

Osteomusculares Relacionados ao Trabalho. In: Sato El (Org). Reumatologia - Guias de Medicina Ambulatorial e Hospitalar UNIFESP / Escola Paulista de Medicina. 2a Ed. São Paulo: Manole, 2010, p. 393-404.

14. Pinheiro FA, Tróccoli BT, Carvalho CV. Validação do Questionário Nórdico de Sintomas Osteomusculares como medida de morbidade. Rev Saúde Pública. 2002;36(3):307-12.

15. Magnago TSBS, Lisboa MTL, Griep RH, Kirchhof ALC, Camponogara S, Nonnenmacher CQ, et al. Condiçōes de trabalho, características sociodemográficas e distúrbios musculoesqueléticos em trabalhadores de enfermagem. Acta Paul Enferm. 2010; 23(2):187-93.

16. Parada EO, Alexandre NMC, Benatti MCC. Lesões ocupacionais afetando a coluna vertebral em trabalhadores de enfermagem. RevLatinoamEnferm. 2002;10(1):64-9.

17. Murofuse NT, Maziale MHP. Doenças do sistema osteomuscular em trabalhadores de enfermagem. RevLatinoamEnferm. 2005;13(3):364-73. 18. Monteiro MS, Alexandre NMC. Work ability and low back pain among workers from a public health institution. Rev Gaúcha Enferm. 2009;30(2):297-302. 19. Elias MA, Navarro VL. A relação entre o trabalho, a saúde e as condições de vida: negatividade e positividade no trabalho das profissionais de enfermagem de um Hospital Escola. RevLatinoamEnferm. 2006;14(4):517-25. 


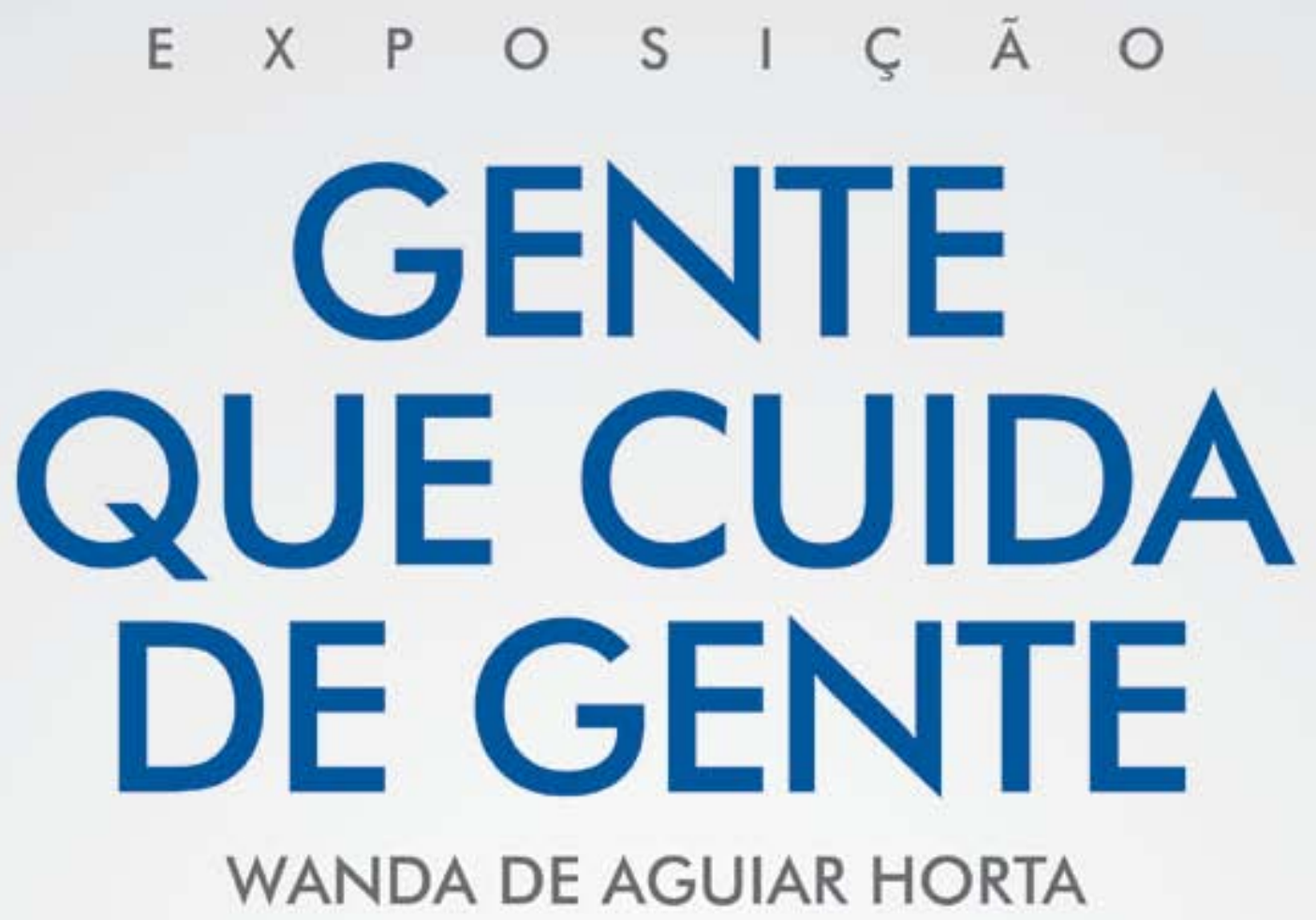

\section{DE 21 DE MARÇO A 27 DE ABRIL}

Galeria do Museu de Enfermagem Anna Nery

Pelourinho

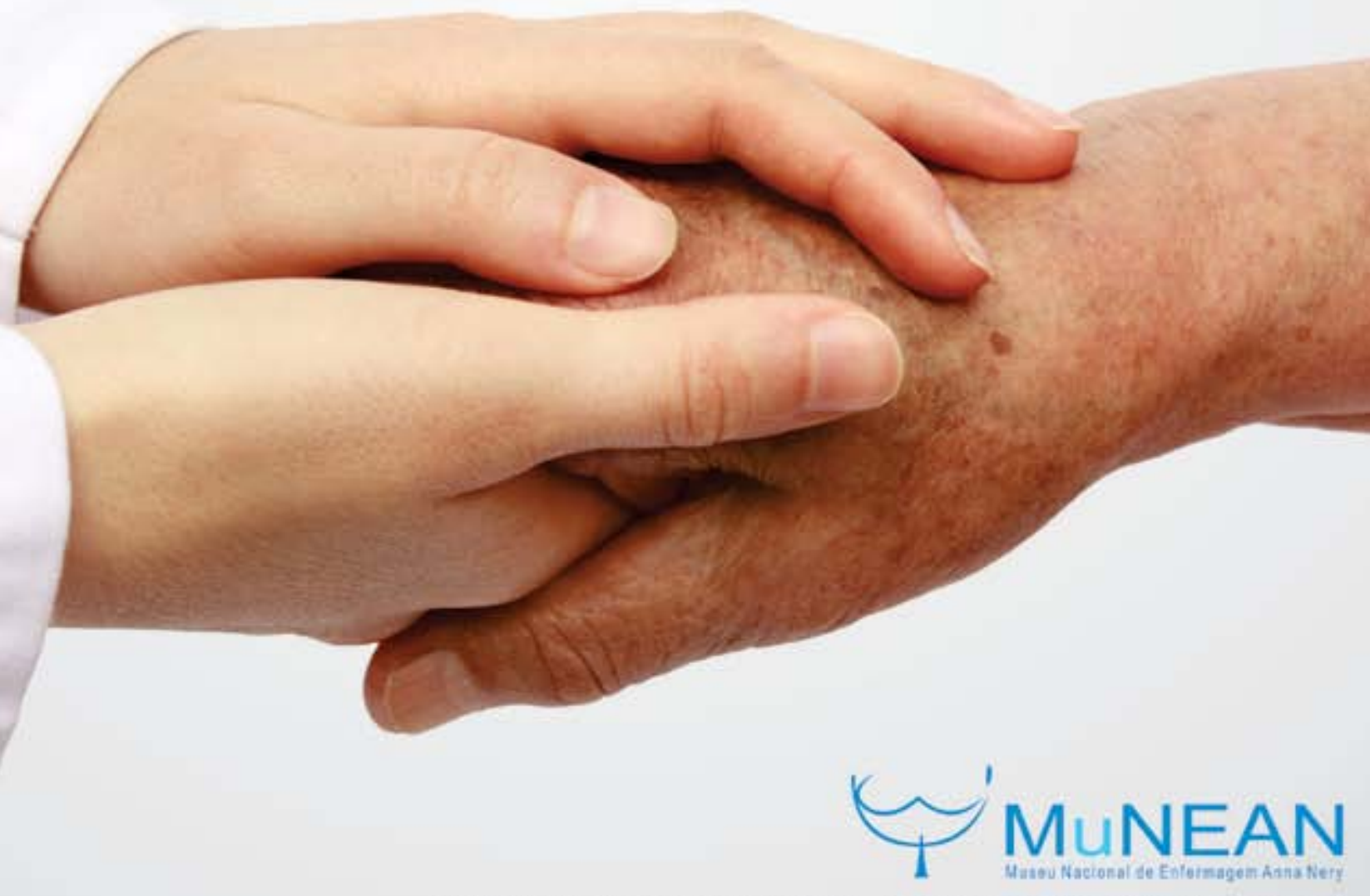

